\title{
Recibiendo injurias y dando las gracias
}

\section{Receiving insults and giving thanks}

\author{
Luisa Fernanda López Carrascal ${ }^{1}$ \\ Universidad de Antioquia (Colombia)
}

Recibido: 16-04-15

Aprobado: 15-06-15

\section{Resumen}

El presente artículo es una aproximación al concepto de humillación a partir de preguntas tales como: ¿cuál es el propósito de aquel que trata al otro como si no fuera un ser humano? ¿Qué relación hay entre el desprecio, la vergüenza y la humillación? ¿Qué/quién define la dignidad de una persona? En primer lugar revisaremos las distintas formas de desprecio que menciona Aristóteles en la Retórica para, posteriormente, analizar la perspectiva normativa de la humillación de acuerdo con las tesis fundamentales de Margalit y Honneth. Finalmente, y a modo de conclusión, se plantearán algunas preguntas que problematizan el vínculo entre el concepto de humillación y el de autorrespeto.

Palabras-clave: Desprecio, Vergüenza, Identidad, Honor, autorrespeto, emociones.

\begin{abstract}
This article presents an approach to define the humiliation concept from questions such as: What is the purpose of him who treats the other as if it were not human beings? What is the relation between contempt, shame and humiliation? What/who define the dignity of a person? First of all, I will review the different forms of contempt that Aristotle mentions in Rhetoric.

\footnotetext{
${ }^{1}$ (luisafernandalc@yahoo.es). Doctora en Filosofía por la Universidad de Antioquia, Colombia. Filósofa de la Universidad Nacional de Colombia. Entre sus publicaciones están: "El arte como testimonio" en Revista Destiempos. México, Distrito Federal. Abril-Mayo de 2015, No. 44; El papel de la imaginación en la educación y la ciudadanía democrática. Santiago, Chile. Facultad de Ciencias de la Educación de la Universidad Central de Chile, 2014; "La enseñanza de las lenguas como escenario para el teatro y la diversidad cultura" en Revista Nudos y Nodos. Bogotá, Universidad Pedagógica Nacional, No. 26, 2009.
} 
Subsequently, I will analyze the normative perspective of humiliation following the thesis proposed by Margalit and Honneth. Finally, I will be raised some questions about the link between the concept of humiliation and of self-respect.

Key-words: Contempt, Shame, Identity, Honor, Self-respect, Emotions.

Conocidísima es la frase de aquel que había envejecido sirviendo a reyes, cuando le preguntaban cómo había llegado a cosa tan rara en la corte, a la vejez: recibiendo injurias, contestó, y dando las gracias.

L.A. Séneca. De ira

\section{Las formas del desprecio}

Durante mucho tiempo humillar fue parte de las obligaciones de los señores, los amos, los emperadores y los reyes, y humillarse ante ellos era una consecuencia natural impuesta por un orden divino respetado y no cuestionado. Dentro de este orden social correspondía poner la vida propia en manos del emperador, porque así correspondía y también por miedo e incluso por cálculo. En De ira Séneca llama la atención sobre la conducta Pastor, "ilustre caballero romano", cuando César encarceló a uno de sus hijos "por la minuciosidad que afectaba en traje y peinado". Después de las muchas súplicas a César para que le perdonase la vida y "cual si la súplica fuese sentencia de muerte, ordenó en el acto que le llevaran al suplicio" (De ira, I, 33). Lo que sucede a continuación es lo verdaderamente asombroso. En un acto más de crueldad, César invita a Pastor a un banquete la noche misma de la muerte de su hijo. Pastor no derramó una lágrima ni dejó ver su dolor. Comió y bebió con entusiasmo en compañía del asesino de su hijo. ¿Por qué? Porque tenía otro hijo. "Las injurias de los poderosos deben soportarse no solamente con paciencia, sino que también con risueño rostro, porque humillarán de nuevo si se persuaden de que han humillado" (De ira, I, 33). Un ejemplo inigualable del estoicismo que pondera Séneca a lo largo de su obra.

Dentro de la concepción estoica, que no reconoce el respeto como algo que es conferido por otros sino por sí mismo, no sólo la ira es irracional, inútil y contra natura; también lo es aquello que la suscita: sentirse despreciado. Una de las consignas fundamentales del pensamiento estoico es que no podemos controlar las condiciones externas, por tanto ningún sentido tiene sufrir por ellas; en cambio sí tenemos control y autonomía sobre nosotros mismos y nuestro espíritu. De aquí que una persona racional no pueda ser humillada 
porque ningún evento externo, emperador o sociedad puede darle razones para ello. Así, en esta suerte de autarquía nadie puede humillar a nadie que no quiera ser humillado, "por ello, el esclavo Epícteto podía tener tanta autonomía espiritual como el emperador Marco Aurelio" (Margalit 1997: 30).

En un contexto en el que la ética ha venido buscando lo que Ernst Bloch llama "utopías sociales" (Honneth 1992), una de ellas a través del derecho natural dirigido a la protección de los derechos humanos y especialmente a eliminar la humillación humana, resultaría cuando menos improcedente la posición estoica. El llamado no puede ser a la autarquía, a volverse inmune ante el maltrato de los demás, a la resignación o a la extirpación de las pasiones. El "hombre interno" o sabio estoico inmune a la actitud de la sociedad y a los lazos de interdependencia entre los seres humanos, no es hoy una opción. Corresponde más bien volver la mirada a Aristóteles quien no invita, de ninguna manera, a estimular el odio o la ira, sino a reaccionar frente al desprecio y la humillación. La impotencia para encolerizarse constituye, según Aristóteles, un defecto y es digno de censura: "El que en tales ocasiones no se irrita, parece no sentir nada, ni saber indignarse justamente" (Ética a Nicómaco, Libro IV. ). Ocasiones para irritarnos son, pues, aquellas en las que somos despreciados ${ }^{2}$. Veamos.

El desprecio es, de acuerdo con Aristóteles, "la opinión sobre algo que no se considera digno de nada convertida en acto" (R, 1378b) ${ }^{3}$. En el libro II de la Retórica señala tres tipos de desprecio: el desdén o menosprecio, la calumnia o malevolencia, y el ultraje. El menosprecio es quitarle todo valor al otro, reducirlo a poco o nada. La calumnia o malevolencia, también entendida como difamación, es una muestra de desprecio; el que calumnia busca los medios para que el otro no logre sus deseos, no para conseguirlos aquel que difama, sino sólo para que el otro no los tenga. Es necesario, pues, despreciar para llevar a cabo acciones orientadas con este simple propósito. Finalmente, el ultraje o el insulto es un desprecio que consiste en hacer y/o decir algo que provoque vergüenza en el otro; el ultraje deshonra ( $\mathrm{R}, 1378 \mathrm{~b})$.

Las distintas formas de desprecio revelan, en últimas, la falta de reconocimiento de valor a quien se desprecia; el desprecio es la negación del otro por distintas vías (menosprecio, humillación, ultraje) para impedir el florecimiento personal o la realización de sus capacidades. De acuerdo con Aristóteles, el proyecto de llevar una vida buena, es decir, orientada de acuerdo con las virtudes, no es algo que se produzca de forma natural; requiere largos periodos de trabajo, de práctica; requiere un esfuerzo moral, pues no ocurre espontáneamente, ni es una cualidad natural. Nadie puede tampoco realizar este proyecto sin los amplios lazos familiares, de ciudadanía y de amistad, ni sin las instituciones políticas

\footnotetext{
${ }^{2}$ La ira es tal vez una de las emociones más interesantes e importantes del conjunto de emociones que Aristóteles estudia en la Retórica, especialmente por su carácter intensamente social y, por tanto, moral.

${ }^{3}$ En el texto se hacen referencias a la paginación estándar del conjunto de la obra aristotélica. 
que le permitan hacerlo. Una vida en comunidad con otros es la única vida que será aceptada como completa por alguien que se considere a sí mismo humano. Justamente insiste Aristóteles en que la vida buena es "una vida que sea suficiente no en relación con uno mismo, con el ser que vive una vida solitaria", sino que lo sea "en relación con los padres, hijos y mujer y en general con los amigos y conciudadanos" (Ética a Nicómaco, Libro I).

El desprecio de los otros es, pues, un obstáculo para la vida en sociedad y para la realización de los propios proyectos $y$, por el contrario, el reconocimiento de la familia, amigos y conciudadanos, contribuye al logro de los mismos.

\section{La perspectiva normativa de la humillación}

En su libro La sociedad decente Margalit (1997) hace un estudio de la humillación desde una perspectiva normativa asociada a una justificación negativa del respeto. Su interés está orientado fundamentalmente hacia la pregunta acerca de cómo evitar el daño o la humillación. En principio, esta perspectiva normativa bien puede constituir una pieza importante para esclarecer la noción del desprecio injustificado, puesto que, como señala Margalit:

en el caso de un acto injustificado de humillación -y todo intento de humillar a una persona está injustificado- la cuestión es si la víctima tiene una razón de peso para sentirse humillada; esto es, para considerar que, a sus ojos, su respeto hacia sí misma ha disminuido (1997: 105).

Aceptaremos con Margalit que las emociones no solo pueden ser causadas sino también justificadas. Dado que su interés es normativo y no psicológico, la humillación aquí no depende de las condiciones de la persona que es humillada: psicológicamente puede haber razones para que la persona se sienta humillada y no sentirse de esa manera; o bien, la persona puede sentirse humillada sin que tenga razones para ello. La humillación aquí tampoco depende de las intenciones del agente, pues no sólo los individuos tienen la capacidad de humillarse entre sí, una sociedad también puede ser humillante. Desde la perspectiva normativa de Margalit, "la humillación no precisa a nadie que humille, de manera que es más importante determinar si hay una justificación para sentirse humillado que llegar a saber quiénes son los que humillan" (1997: 110).

La humillación, en esta acepción normativa, es la combinación de una razón general de peso con el hecho de que la persona se siente humillada. Rastrearemos, pues, la búsqueda que hace Margalit de aquello que le da a la persona una buena razón, y no sólo una causa, para sentirse humillada.

Al explorar cuáles pueden ser las buenas razones para que una persona considere que se le ha humillado, Margalit encuentra que las respuestas en 
función de violación de derechos humanos podría ser una opción. Sin embargo, de una argumentación imprecisa y poco clara, Margalit deduce que el concepto de derecho no es necesario, ni suficiente, para fundamentar una sociedad decente, entendida como una sociedad que no humilla a las personas que están bajo su órbita. Dice Margalit que es insuficiente porque podría darse el caso de una sociedad que respete los derechos humanos y no los derechos civiles. Esto, sin embargo, es una imprecisión, pues los derechos civiles son derechos humanos. Margalit recurre al voto como ejemplo de un derecho civil (que por lo demás no es civil sino político) que, dice él, no es un derecho humano. De aquí concluye que una sociedad que priva a las mujeres del derecho al voto no es una sociedad decente a pesar de que respete los derechos humanos. Sin embargo, resulta cuando menos confuso el sentido en que Margalit habla en este contexto de los derechos humanos, pues cuando no se le permite a las mujeres ejercer el derecho al voto se están violando sus derechos humanos, ya que la no discriminación es un principio transversal en el derecho internacional de derechos humanos. Sigue siendo inquietante la afirmación de Margalit de que se pueden violar los derechos civiles sin violar los derechos humanos, especialmente al ser este su único argumento para demostrar que una sociedad que respete los derechos humanos no es condición suficiente para considerarla una sociedad decente.

Posteriormente Margalit examina la posibilidad de caracterizar la sociedad decente en términos del honor social, esto es, una sociedad que otorga a cada persona el honor que se merece; su intención es además "rehabilitar la idea del honor en las discusiones políticas, en lugar de considerarlo una mera reliquia del pasado" (1997: 45). No obstante, uno de los problemas que aquí se presenta, siguiendo la argumentación de Margalit, es el de que los honores sociales, para distribuirse justamente, suponen una graduación y un criterio de logro -como "recompensa"- (si se concedieran a todo el mundo el concepto de honor social sería vacío, señala Margalit); y el honor que interesa es uno que se garantice a todas las personas por igual, por lo que son, y no uno que sea graduable, por lo que hayan hecho (1997: 46). Queda así descartado que el concepto de humillación a través del cual podemos decir de una sociedad que es decente, no es la carencia de honor social. En cambio, en el honor intrínseco, es decir, en el honor como dignidad sí se encuentra el tipo de razón que busca Margalit. Aunque históricamente el honor social precede al honor como dignidad, la primacía conceptual la tiene este último: "El honor como dignidad, dice Margalit, es un tipo de honor que las personas deben tener, y su violación es una razón para sentirse humillado" (1997: 46).

En el uso del concepto de honor como dignidad Margalit parece coincidir con Honneth: aquello que lo llevó a recuperar la idea de la lucha por el reconocimiento fue el punto de vista del honor y el respeto que adoptaron 
ciertas tendencias historiográficas de las décadas de los 60, 80 y 90, más que los movimientos sociales que combaten por el reconocimiento de su diferencia cultural. Su interés en la lucha por el reconocimiento parte de la manera como los movimientos obreros vinculaban sus reivindicación al concepto de honor. Para ellos lo que debía respetarse era su forma específica de actividad (su modo de autorrealizarse) y sus propias prácticas culturales (2009: 47). Honneth entiende el honor, al igual que Margalit, derivado de la dignidad:

\begin{abstract}
Por «honor», «dignidad» o, dicho con un término moderno, por «status» de una persona se entiende la medida de aprecio social que corresponde a su modo de autorrealizarse en el horizonte de la tradición cultural de una sociedad; si esta jerarquía social de valores estuviera constituida de manera que desprestigiara formas de vida o convicciones individuales considerándolas de menos valor o defectuosas, entonces se quitaría al sujeto afectado toda posibilidad de atribuir un valor social a sus propias capacidades (Honneth 1992: 82).
\end{abstract}

Es, pues, en virtud del honor intrínseco que es posible exigir el honor social (no como recompensa, sino como reconocimiento). En términos de Margalit, el honor social es aquello que la sociedad le otorga a las personas, mientras que el honor intrínseco, el respeto a uno mismo, es el honor que las personas se otorgan en virtud de su propia humanidad, esto es, por su rasgo de pertenencia a la comunidad humana. Dice Margalit: "En síntesis, el concepto de honor relevante para la sociedad decente es el concepto de dignidad humana. Éste es un tipo de honor que las personas deberían tener, y su violación es una razón para sentirse humillado" (1997: 46).

Las consideraciones precedentes constituyen el tipo de reflexión que conduce a Margalit a proponer su definición normativa de la humillación: "La humillación es un tipo de conducta o condición que constituye una buena razón para que una persona considere que se le ha faltado al respeto" (1997: 21). Observamos así que esta noción lleva consigo que el respeto es lo contrario de la humillación:

Para que sea conceptualmente posible percibir como un acto humillante el rechazo de un ser humano de la "Familia del Hombre", tiene que haber un supuesto subyacente relativo al respeto básico debido a los seres humanos tal que desviarnos de él produzca humillación. La humillación es un concepto que se basa en un contraste, y lo opuesto a la humillación es el concepto de respeto hacia los humanos. Si no hay concepto de dignidad humana, no hay tampoco concepto de humillación (Margalit 1997: 124).

Ahora bien, si aceptamos que la humillación tiene un vínculo conceptual especial con el respeto (derivado del de dignidad humana), podemos preguntarnos por las bases del respeto: ¿qué aspecto de los seres humanos justifica el respeto 
a los seres humanos, como un respeto básico y general? Margalit explica tres tipos posibles de respuesta. Por una parte, la justificación positiva del respeto acepta la pregunta y se detiene en la búsqueda de una característica (o varias) en virtud de las cuales todas las personas sean merecedoras de respeto. Por otra parte, se encuentra la respuesta que es escéptica frente a la existencia de tal característica, y considera que no hay ningún rasgo que justifique el respeto; hay sí una actitud de respeto hacia los seres humanos en virtud de la cual el hecho de ser humano justifica (escépticamente) el respeto (Margalit 1997: 120). La actitud de respeto es una actitud que tenemos ante los otros, otros a quienes reconocemos naturalmente como seres humanos. No hay nada anterior a la actitud natural de respeto que es, más bien, el punto de partida, replica el escéptico. La tercera respuesta, que es la justificación negativa del respeto, es la que adopta Margalit al preguntarse, no por una característica de los seres humanos por la que haya que respetarlos, sino simplemente por qué es malo humillar a los seres humanos. El autor basa su justificación negativa

en el hecho de que los seres humanos son criaturas capaces de sentir dolor y de sufrir no sólo como resultado de actos físicamente dolorosos, sino también como resultado de actos con significado simbólico (...) el peor de los males es la crueldad (...) la humillación es crueldad mental (Margalit 1997: 77).

No es tan solo el dolor físico lo que justificaría la no humillación, pues también otros animales no humanos lo sienten, sino que es en el dolor psicológico o simbólico donde reside la humillación; solo las personas sufren el tipo de crueldad que supone la humillación. Esto queda expresado en una de las entrevistas hechas a Primo Levi en la que le preguntaron por qué creía que tantos alemanes le dieron especial importancia al episodio narrado en su libro Si esto es un hombre en el que el guardián de las SS se limpió las manos en su camisa. Levi responde resaltando justamente el aspecto simbólico de este hecho:

No se trató de un acto doloroso: un golpe en la cara habría sido mucho más doloroso. La cuestión fue que aquel hombre me utilizó como un trapo. Entonces, y también ahora, lo percibí como una de las ofensas más graves de que fui víctima (Levi 1997:180).

El dolor que se sufre en la humillación es un dolor psicológico, en esto concuerdan Margalit y Honneth cuando este último resalta la diferencia entre una herida física y una moral; esta última resultado de una injusticia, del menosprecio, en últimas, de la humillación. Dado que la crueldad, del tipo que sea, es mala, y dado que la conducta que evita la crueldad es el "ejemplo paradigmático de la conducta moral", sostiene Margalit, no necesitamos más justificación. 
Podríamos concluir parcialmente que el dolor que se expresa en la humillación es un dolor "moral" resultado de la falta de reconocimiento. Sin embargo, será necesario precisar a qué clase de reconocimiento nos estamos refiriendo. En Margalit se trataría del reconocimiento de nuestra pertenencia a la "Familia del Hombre", a lo que volveremos más adelante. Por el momento, el trabajo de Honneth en torno al concepto de reconocimiento vinculado al desprecio como herida moral, nos dará mayores luces para comprender este aspecto.

Según Honneth, la experiencia del reconocimiento recíproco es la posibilidad, tal vez la única, para lograr una relación satisfactoria con uno mismo, convicción esta que nos obliga a asumir mayor conciencia y responsabilidad respecto al ultraje y menoscabo de la dignidad propia y de los otros. No debe sorprendernos, pues, que ante la falta de la reconocimiento se produzca en la persona lo que Honneth llama un "vacío psíquico"

(...) que buscaría expresarse mediante reacciones afectivas de índole negativa como la vergüenza o la ira, el ultraje o el menosprecio. De ahí que la experiencia del desprecio vaya acompañada siempre de sensaciones afectivas que pueden revelar al individuo, por principio, que le son negadas determinadas formas de reconocimiento social (1992: 88).

Honneth parte de Hegel y Mead para su análisis del reconocimiento en relación con el desprecio: "para la realización de su vida, el sujeto humano requiere necesariamente del respeto o de la valoración de su contraparte en la interacción" (Mead 1992: 7). Cuando no ocurre tal reconocimiento en vista de un desprecio intencional e injustificado, como dice Aristóteles, aparecen las "heridas morales". Estas heridas, o daño, o sufrimiento moral ("pesar" en la definición de Aristóteles) puede tomar la forma de ira. Podemos asumir que el desprecio al que se refiere Aristóteles en su definición de la ira hace alusión a una herida moral y que corresponde a lo que Honneth entiende como la negación del reconocimiento:

\begin{abstract}
(...) una herida física se transformará en una injusticia moral si la víctima percibe en ella una acción que intencionalmente desdeña su bienestar en un aspecto esencial. El dolor corporal como tal no constituye aquí la condición del sufrimiento moral, sino ante todo la conciencia concomitante de no ser reconocido en la propia idea de sí (Honneth 1996: 9).
\end{abstract}

Así, el punto de partida para una concepción de la moral social debe ser el análisis fenomenológico de los daños morales que ocurren en las distintas formas de interacción. Basándose en la división que hace Hegel (familia, Estado y sociedad), Honneth establece tres formas (esferas) de reconocimiento a las que subyacen las luchas entre los individuos para hacer valer las reivindicaciones de su identidad. A cada una de estas formas de reconocimiento le corresponde una 
herida moral o, lo que es lo mismo, una forma distinta de desprecio. La primera esfera de reconocimiento corresponde al amor o el cuidado y su desprecio se refiere al daño a la integridad física, la segunda es el respeto moral que se identifica con el Estado democrático de derecho en el que los ciudadanos reciben un trato igual. Y la tercera corresponde a la estima social o solidaridad, esfera en la cual compartimos y reconocemos los valores de los demás de acuerdo a sus capacidades y proyectos de vida. (Honneth 2009: 28). Detengámonos por lo pronto en la primera y más fundamental forma de desprecio que es la que se refiere a la integridad física de la persona, "el estrato más básico de seguridad emocional y física en la exteriorización de las necesidades y los sentimientos propios" (Honneth 2009:25), aquella en la que por la fuerza es retirada cualquier posibilidad de decisión sobre el propio cuerpo.

Lo peculiar de estas maneras de vulneración física, como ocurre con la tortura o con la violación, no es que impliquen dolor corporal propiamente dicho, sino su unión con el sentimiento de estar expuesto indefenso a la voluntad de otro sujeto hasta la privación consciente de la realidad (Honneth 1992 : 81 . Subrayado nuestro).

¿En dónde radica el desprecio o la humillación en esta forma de no reconocimiento? Vimos que en Margalit la humillación como daño moral se refiere a una herida de carácter simbólico, lo que le permite afirmar que es exclusiva de los seres humanos. Honneth reconoce este carácter simbólico y añade el estar expuesto e indefenso a la voluntad del victimario que en su trato lo está excluyendo de la "Familia Humana". Veámoslo con más detalle.

\section{Humillación y vergüenza}

Un ejemplo que ilustra la primera forma de desprecio, vinculado a la explicación de Margalit respecto a la humillación en su carácter simbólico o psicológico, nos lo ofrece la película This must be the place (2011) de Paolo Sorrentino. Allí un judío busca infructuosamente durante 30 años a quien fuera su torturador en los campos de concentración. Tras la muerte del judío, su hijo decide reemplazarlo en la búsqueda. Cuando finalmente lo encuentra, el nazi le cuenta las razones del odio de su padre hacia él, quien dice no haberlo maltratado nunca. Simplemente mientras los judíos estaban formados azuzó a su perro para que le mostrara su fiereza, ante lo cual el judío sintió miedo y se orinó en los pantalones. Esto provocó la risa del nazi. No hubo más. Pero fue suficiente para que se evidenciara la situación de vulnerabilidad y humillación (como crueldad psicológica) en la que se encontraba, es decir, estaba "expuesto indefenso a la voluntad de otro". Los 30 años de búsqueda se hacen necesarios en el judío para recuperar su dignidad, pues quien 
se la ha quitado es quien se la debe devolver. El hijo, a pesar de haber comprado una pistola para cobrar venganza, no lo mata, sino que lo obliga a desnudarse y salir a la nieve a unos pasos de su casa. La imagen del hombre viejo y enfermo, encorvado, con la mirada gacha y tapándose lo que puede con sus manos, es lo que suponemos significa la restauración de la dignidad del padre ya muerto, no la vida misma o el maltrato físico al torturador.

Este ejemplo no sólo revela aquello en lo que Honneth insiste frente a la vulnerabilidad, sino también el vínculo conceptual y causal entre la vergüenza y la humillación (como crueldad psicológica) al que se refiere Margalit. Margalit ilustra esta relación a través de un artículo de diario en el que se describe la humillación de los reclutas en el ejército: un sargento ordena a un soldado a tomar agua hasta vomitar y aún así lo obliga a seguir bebiendo. Otras actitudes de este sargento y de un cabo son descritas y, finalmente, dice el párrafo que cita Margalit: "se burlaron de otro soldado que tartamudeaba imitándolo en público" (1997: 79). Esto le sirve a Margalit para confirmar su tesis de que solo los seres humanos somos capaces de padecer "el tipo de crueldad que supone la humillación (por ejemplo, si imitan nuestro tartamudeo) y una sociedad decente es aquella que erradica los abusos, siendo la humillación una forma concreta de abuso" (1997: 79) ${ }^{4}$.

Autores como Miller (Nussbaum 2006) distinguen la vergüenza de la humillación en tanto que esta última produce risa, mientras que la vergüenza produce lástima. Sin embargo, y como vimos en nuestro ejemplo del judío, la vergüenza no se distingue de la humillación. La vergüenza es una forma de humillación y la risa (la burla) incrementa la indefensión comprometiendo aún más la dignidad del judío. Dice Aristóteles: “(...) nos avergonzamos ante quienes emplean su tiempo en los yerros de sus semejantes, como los burlones o los autores de comedias, pues éstos son en cierto modo maledicentes y dados a propalar chismes" ( $\mathrm{R}, 1384 \mathrm{~b})$.

\section{Humillación e identidad}

Humillar a alguien es en muchas situaciones avergonzarlo y avergonzar es humillar (Nussbaum 2006). Si bien, como en los ejemplos mencionados, tanto la humillación como la vergüenza pueden presentarse de manera simultánea, podemos entender la vergüenza desde una perspectiva personal,

\footnotetext{
${ }^{4}$ Episodio este que nos recuerda lo descrito por Evelio Rosero en su novela Los ejércitos (2007) cuando los ejércitos (nunca sabemos cuáles, tal y como ocurre en la realidad colombiana) llegan al pueblo a esparcir el terror y todos huyen como pueden. El anciano Ismael está en la plaza cuando escucha los disparos que pasan silbando por su cabeza. Se tira al piso. Uno de los soldados le dice: “-Oiga viejo, ¿quiere que hagamos un tiro al blanco con usted?/ -Aquí -les digo, y me señalo el corazón. / No se qué les causa risa de nuevo: ¿mi cara?, otra risotada me respondió”. Nos recuerda también las tortura en Abu Grahib; Susan Sontag hace un análisis agudo en su artículo "Ante la tortura de los demás" (2004b), posterior a su libro Ante el dolor de los demás.
} 
esto es, como un sentimiento que aparece tras una evaluación individual: he fallado de acuerdo a mis propios estándares. Esta evaluación surge a partir de la opinión de otros que pueden no estar presentes, pero sentimos como si existieran espectadores o jueces externos: "La vergüenza se desarrolla sólo con la conciencia y la conciencia de valor de sí mismo y del individuo como consecuencia de la percepción de la relación de esto con nuestra existencia de especie" (Scheler 2004: 148. Subrayado en el original). Aquí es posible descubrir tanto la primera como la tercera esfera de reconocimiento que señala Honneth y que corresponden a la autoconfianza y a la autoestima.

Si bien la vergüenza, aunque suponga siempre la mirada de otros, puede ser en algunas ocasiones más íntima y personal (individual, como dijimos arriba), la humillación siempre supone la presencia de otro (quien humilla) y en algunas ocasiones de otros (quienes presencian la humillación). De acuerdo con Klein (en Hartling y Luchetta 1999), todos hemos participado alguna vez de al menos uno de los tres roles que supone la humillación aunque recordemos con más intensidad el rol de humillado; los otros dos son el de humillador y el de testigo de la humillación. Este último, lo sabemos todos, es fundamental en el acto de humillar, pues cuantas más personas me observen degradado, confundido, violado o paralizado, mayor es el grado de pérdida de valor propio y mayor es el poder que ejerce el humillador frente a la víctima y los testigos. Dice Aristóteles: "Por eso nos da más vergüenza de quienes van a estar más tiempo con nosotros o nos prestan atención porque en ambos casos estamos ante sus ojos" (R, 1384b).

Volviendo a las categorías de Honneth, lo que está presente en la humillación es la negación del reconocimiento, de otros, pero también de sí mismo. El autorreconocimiento y la autoconciencia, así como el reconocimiento y la dignidad, presuponen la intersubjetividad ontogenética, esto es, su origen social. El daño moral, insistimos, es un daño a la capacidad de autorreferencia moral, de autorrepresentación, adquirida intersubjetivamente; así, lo que resulta lesionado cuando se ve afectado el autorrespeto de la persona humillada es una relación positiva de la persona consigo misma, esto es, su identidad.

La construcción de la identidad supone necesariamente la existencia de los otros en tanto que interiorizamos sus opiniones, evaluaciones y expectativas. Por supuesto hay unos "otros" más significativos y son sus expectativas y opiniones las que realmente interiorizamos. Pero cada uno de estos "otros" forman un "otro generalizado" que, a su vez le da forma a nuestro "sí mismo" (Mead, 1973). Por tanto, la pregunta por la identidad no es ¿quién soy yo?, sino ¿quién soy yo para los demás? (Tugendhat 1990). En palabras de Erikson "el individuo se juzga a sí mismo a la luz de lo que percibe como la manera en que los otros lo juzgan a él” (1968: 22). En este sentido la humillación es una construcción social, pues está anclada a las nociones de autorrespeto y 
autoestima, nociones que se construyen en estrecha reciprocidad con la mirada y los sentimientos de los otros.

Así, el criterio para determinar y delimitar las patologías sociales es, para Honneth, el reconocimiento recíproco en las tres esferas del reconocimiento. El criterio para determinar si una sociedad es decente es, de acuerdo con Margalit, si sus instituciones humillan a los ciudadanos. La humillación consiste básicamente en no reconocer al otro como miembro de la "Familia Humana" o, lo que es lo mismo, tratarlo "como si no fuera humano". Veamos los alcances de esta afirmación.

\section{Ser tratado como si uno no fuese humano}

Del plano de la justificación Margalit pasa al plano del contenido conceptual de la humillación que, ya sabemos, está vinculada con la falta de respeto. Los tres sentidos del concepto de humillación que Margalit reconoce están atravesados con la justificación negativa del respeto que esbozamos atrás: tratar a los seres humanos como si no fueran seres humanos, realizar acciones que manifiestan la pérdida de control básico, y el rechazo de un ser humano de la comunidad humana. El sentido que Margalit considera más básico y general es el tercero por cuanto incluye los otros dos. Tratar a los seres humanos como si no fueran seres humanos, como si fueran objetos, animales o seres inferiores, es un modo de excluirlos de la "Familia del Hombre", esto es, de la comunidad humana. Tenemos entonces que para Margalit la idea central de la humillación como el rechazo de una persona (o grupo de personas) por parte de la comunidad humana incluye la humillación que se encuentra en el tratar a otro ser humano como si no lo fuera. Esto refuerza su idea del carácter simbólico de la herida moral.

Veámoslo a la luz de dos ejemplos que menciona Martha Nussbaum en su libro La terapia del deseo (2003) como parte de su análisis sobre la cólera pública.

(i) Frente a las nuevas pruebas de tortura de civiles en Kuwait que se encontraron en la última etapa de la guerra del Golfo, el general a cargo afirmó no poder decir nada respecto a quienes perpetraron tales actos. El silencio ante el desconcierto puede ser una respuesta válida; sin embargo, después agrega que aquellas personas que cometieron semejantes acciones "no parecen pertenecer a la especie humana tal como nosotros la conocemos y reconocemos" (Nussbaum 2003: 498). Si bien el general está condenando las acciones brutales de los victimarios, esta condena la hace bajo la distinción "humanos como nosotros" y "humanoides", como lo describiera Rorty en su artículo "Derechos humanos, racionalidad y sentimentalismo" (1995). Probablemente esta misma distinción la usaron aquellos que infligieron las torturas. 
En su artículo, Rorty nos recuerda los asesinatos y violaciones por parte de aquellos que dicen haber actuado en defensa de la "verdadera humanidad" al liberar o purificar al mundo de una pseudohumanidad. Los verdaderos humanos, según ellos, son "personas como nosotros". Los que son diferentes a nosotros están en otra categoría. Parecen seres humanos pero no lo son, son "humanoides" disfrazados. Esta idea les permite torturar, violar y asesinar, porque "no son seres humanos". Son "cucarachas tutsi" decía Kayibanda en la masacre de Rwanda; son perros circuncisos, decía el serbio sobre los musulmanes. Durante el holocausto se partió de la idea de que los judíos no eran seres humanos ${ }^{5}$.

Es esta distinción, que nace precisamente de la búsqueda de una escencia de los seres humanos que los haga merecedores de derechos, justa y paradójicamente, la que ha permitido avalar asesinatos y violaciones por parte de aquellos que dicen haber actuado en defensa de la "verdadera humanidad" al liberar o purificar al mundo de una pseudo-humanidad. Recordemos las cínicas palabras de Himmler en su discurso en Posen:

No debemos ser duros y despiadados si no es necesario, está claro. Nosotros los alemanes, que somos los únicos en el mundo que tenemos una actitud decente con los animales, debemos también adoptar una actitud decente con estos animales humanos, pero sería un crimen contra nuestra sangre preocuparse por ellos o darles un ideal.

El general de la historia de Nussbaum afirma, con aparente indignación, que aquellos que obraron de esa manera no pertenecen a nuestra clase civilizada de humanos. Es fácil y también peligroso deslizarse de la ira ante la deshumanización, a la ira que establece la diferencia entre humanos y bárbaros. Imposible no recordar la famosa cita de Levi Strauss "Salvaje es quien llama salvaje al otro".

(ii) Sobre la violación, mutilación y asesinatos de mujeres y niños en Vietnam, la explicación de tales acciones, dice Nussbaum, parece radicar en que los soldados norteamericanos están frustrados, desgastados, desesperados y culpan de esta situación a los vietnamitas: "Después de meses de frustración y sufrimiento en la jungla, la invitación a la venganza resulta agradable" (2003: 498). Pero para vengarse necesitan distanciarse de la humanidad del otro, necesitan des-humanizarlos, esto es, verlos como si fueran monos amarillos, bultos o trozos de carne. Esas son justamente las palabras del oficial Calley respecto a la matanza en My Lai:

El haber matado a aquella gente en My Lai no me obsesiona en absoluto. No lo hice por el placer de matar. En realidad, no estábamos allí para matar seres

${ }^{5}$ Véase la reflexión de Nussbaum (2008) sobre el asco, la vergüenza y la compasión. 
humanos sino para matar una ideología defendida por, no lo sé, piezas, bultos, trozos de carne. Yo no estaba en My Lai para destruir hombres inteligentes, estaba allí para destruir una idea intangible ${ }^{6}$.

Las investigaciones de Zimbardo (2008) concluyen que las situaciones en las que los soldados ejercen sus trabajos pueden conducir a las humillaciones y vejaciones como las que se dieron en My Lai y Abu Ghraib ${ }^{7}$. El comportamiento grupal, la deshumanización y la desindividuación, las dinámicas de poder, conformidad y obediencia son elementos que permiten lo que Bandura (1999) llamó "desvinculación moral". Este concepto hace referencia al fenómeno de racionalización a través del cual los individuos se deshacen de los estándares de conducta ética a los que se adhieren usualmente, para poder participar de actos inhumanos y poco éticos. Al igual que Zimbardo, Bandura sostiene que en condiciones normales la mayoría de nosotros no somos capaces de llevar a cabo semejantes actos de crueldad, ya que contamos con una serie de mecanismos de auto-regulación que motivan el comportamiento moral. Pero en condiciones determinadas estos mecanismos se desactivan produciendo una suerte de carencia de sentido o compromiso moral. De esto fue testigo Levi, quien afirma que:

El mejor modo para defenderse de la invasión del recuerdo es impedir su entrada (...). Para eso servirán muchos de los artificios elegidos por los jefes nazis para proteger la conciencia de quienes estaban dedicados a los trabajos sucios (...) se les distribuía alcohol a voluntad, de manera que la matanza fuera velada por la embriaguez (...) los bien conocidos eufemismos ("solución final", "tratamiento especial”, (...) "unidad de Emergencia” (2000: 28).

En efecto, los mecanismos de desactivación pueden ser de distinto orden. Uno de ellos, como bien menciona Levi, la reinterpretación de la conducta a través del uso de lenguaje eufemístico. Palabras como "tortura" o "ejecución" envían nociones que nos remiten a un marco ético, pero otras palabras pueden no tener el mismo efecto y significar lo mismo: "técnicas de interrogatorio avanzadas", "ejecuciones extrajudiciales" o "neutralización de la amenaza". Emilio Meneses, Oficial de Reserva de la Armada de Chile durante la dictadura, no reconoció durante muchos años haber torturado; reconocía sí, haber sido "interrogador" y "clasificador". Finalmente, en el año 2001, tuvo que aceptar lo evidente cuando dijo al diario electrónico El mostrador: "Lo que pasa es que hoy definimos esto como tortura. En aquel entonces no se hablaba de tortura. Se decía: maltrataron a este tipo, lo apremiaron. Ahora, que efectivamente hubo

\footnotetext{
${ }^{6}$ Tomado de Diario La República: http://www.diariolarepublica.com.ar/notix/noticia php? $\mathrm{i}=101716 \& \mathrm{f}=2006-06-02$. Consultado el 16 de julio de 2014.

${ }^{7}$ Las primeras conclusiones fueron extraídas a partir de su famoso experimento "Carceleros y reclusos" (Zimbardo, Haney, Banks y Jaffe, 1986)
} 
tortura en el Estadio Nacional, no me cabe duda que la hubo" (Garretón 2004: $143)^{8}$.

Igual de indignante fue la declaración del Secretario de Defensa estadounidense Donald Rumsfeld frente a las fotografías de torturas en Abu Ghraib: aceptó que los prisioneros hubieran sido objeto de "maltrato" y en última instancia de "humillaciones", pero no de tortura. El maltrato, clasificación o retención como acciones que no implican tortura, según las anteriores declaraciones, conllevan otras medidas como la prohibición de lavarse o usar los baños, lo cual hace que enseguida sean considerados por los demás como infrahumanos y así resulte más sencillo torturarlos y matarlos (Rozin en Nussbaum 2008).

Actuar como si en nuestro análisis puede tener dos sentidos o propósitos: o bien para humillar haciendo sentir al otro que es aquello que el victimario quiere que sea, es decir, un mono, un perro, una pieza; o bien para distanciarse de la humanidad de la víctima y poder torturar y asesinar a quienes no son, a sus ojos, seres humanos. Esto último supondría, siguiendo los análisis de la desvinculación moral de Bandura (2002), que el como si opera como un dispositivo emocional que en situaciones extremas permite desactivar el sentimiento de culpa y empatía. Sin embargo, tratar a los seres humanos como si no fueran seres humanos no es verlos perceptualmente como no humanos, ni creer que no lo son. Salvo en casos patológicos muy excepcionales como el de la ceguera al aspecto humano (Margalit 1997), no creemos que la otra persona no sea humana; es decir, cuando tratamos a otra persona como si no fuera humana sabemos perfectamente que sí es un ser humano. La humillación, como dice Margalit, presupone la humanidad del humillado. En la medida en que el que humilla sabe bien que rechaza a una persona humana, su actitud es una postura artificial: "se rechaza siempre a una persona y esto lo sabe bien quien humilla” (Margalit 1997: 97).

Aquí reside buena parte del horror de las situaciones de crueldad: las personas responsables saben muy bien que están tratando con seres humanos. El teniente Calley sabe muy bien que aquel a quien dispara no es un bulto, incluso Himmler tuvo que admitir que matar personas en los campos de concentración no era lo mismo que matar ratas, aunque la propaganda nazi insistiera en que los judíos eran como ratas que envenan no los pozos sino la cultura. El victimario sabe muy bien que no está frente a piezas o animales, lo que pretende es mostrarle al otro que depende de él, de su torturador, que quede excluido de la comunidad humana. En esto consiste la humillación.

\footnotetext{
8 Hasta ese momento (2001) Emilio Meneses, Doctor en Relaciones Internacionales de la Universidad de Oxford, llevaba adelante una brillante carrera académica como profesor encargado de la Cátedra de Postgrado en Defensa del Instituto de Ciencia Política de la Universidad Católica de Chile, que se financiaba mediante becas entregadas por el Ministerio de Defensa. Después de la denuncia de Felipe Agüero, quien fue torturado por él en el Estadio Nacional, tuvo que alejarse de su vida académica.
} 


\section{Observaciones finales: reconocimiento, humillación y autorrespeto}

La humillación como la deliberada imposición de una pérdida total de la libertad y de control de los propios intereses vitales constituye otro de los sentidos del concepto que considera Margalit (en Honneth, como vimos, es ese "estar expuesto a la voluntad del otro"). A una persona se le niega su capacidad de actuar libremente de dos maneras. Margalit retoma la noción de Berlin de pérdida de libertad como una intervención externa radical en la capacidad de un ser humano de desplazarse, cuando por ejemplo la persona está físicamente atada y pierde su capacidad de acción. Pero negarle a una persona su capacidad de ser libre puede bien significar la pérdida de su control para modelar la propia vida y lograr la autorrealización, es decir, para decidir su forma de expresar su humanidad. Sin embargo, lo que es específico de la pérdida de control como modo de humillar a los seres humanos, dice Margalit, no es sólo la crueldad del confinamiento físico, sino como ya lo hemos repetido, el elemento simbólico que expresa la subordinación de la víctima9 ${ }^{9}$.

Anteriormente se indicó que para Margalit la humillación como pérdida del control sobre sí mismo está contenida en su idea central de la humillación como rechazo de la comunidad humana. Su argumentación procede del siguiente modo: la falta de respeto como falta al autorrespeto que aparece en la pérdida del autocontrol significa tratar al otro como si no fuera un ser humano en el sentido en que no se le ve como un agente libre, negarle la posibilidad a la persona de actuar libremente significa rechazarla en tanto que ser humano. El respeto al autocontrol de la propia persona es un componente del respeto que se le debe a los seres humanos en tanto que humanos ${ }^{10}$.

Pero ¿qué ocurre cuando aquel que es humillado no tiene una buena razón para sentirse humillado o no ve en quien le humilla la intención de hacerlo? Para referirse a la relación entre el autorrespeto y los derechos Margalit recurre al ejemplo del tío Tom como caso paradigmático de aquel que carece de respeto por sí mismo, pues el tío Tom ama a su señor y es fiel a él. En esta lectura de

\footnotetext{
${ }^{9}$ La tortura contiene todos los elementos que hemos considerado propios de la humillación: el trato como si la víctima no fuera un ser humano, la pérdida del autocontrol y el sometimiento a la omnipotencia del verdugo. Esta forma de crueldad física, de acuerdo con Margalit (y también de Honneth), es la forma más primitiva de crueldad, quiebra la confianza en los otros y en el mundo (hasta la pérdida del sentido que el mundo tenía), pone de manifiesto el poder absoluto del otro sobre la víctima impotente y es tal que la violencia y el daño cualifican la relación entera entre el verdugo y su víctima y supera el ámbito de significación que nos ofrecen categorías como humillación o desprecio.

${ }^{10}$ Un análisis interesante que problematiza la perspectiva de Margalit es el que realiza Ángela Uribe (2007) al examinar la situación de los negros en el Nuevo Reino de Granada. Su análisis revela que el énfasis de Margalit en el contenido normativo de la humillación, en detrimento de su contenido psicológico (léase emocional), ofrece sólo una aproximación parcial de por sí insuficiente para comprender la humillación. El eje de su crítica consiste en mostrar el carácter problemático que tiene hacer de la humillación un concepto dependiente o derivado del de respeto.
} 
Margalit, dado que el tío Tom no tiene derechos, éste no siente que se le ha faltado al respeto y, por tanto, no siente rabia hacia su amo.

Ahora bien, supongamos que ya no el sumiso tío Tom, sino otro esclavo que sea consciente de su sufrimiento, pero que sea devoto de Dios, puede no ver en el maltrato sufrido una injusticia, sino una "pueba de Dios", tal y como ocurrió con Job. Todo lo que ocurre (justo o injusto) es la voluntad de Dios y debemos obedecer. Después de todo, "Bienaventurados los que tienen hambre y sed de justicia, pues ellos serán saciados", "Bienaventurados aquellos que han sido perseguidos por causa de la justicia, pues de ellos es el reino de los cielos" (Mateo, 5:5-15). De aquí la interpretación que hace Margalit de Nietzsche respecto a la imposibilidad real de la autarquía del esclavo. Solo alguien muy cercano a la santidad podría soportar toda humillación o ser inmune a ésta. Las personas de un estatus social inferior soportan el maltrato con la esperanza de un posterior castigo divino. Pero no es verdad que la supuesta autarquía del esclavo esté exenta de resentimiento o deseo de venganza: para el católico humillado "[e]1 infierno es la venganza, saturada de resentimiento" (Margalit 1997: 33). Recordemos la frase de Séneca, quien con más fuerza proclama tal autarquía: "tantos esclavos, tantos enemigos". El autorrespeto, afirma Margalit siguiendo a Nietzsche, requiere de confianza social; es tal vez por ello que los aristócratas sí pueden, eventualmente, ignorar o despreciar la opinión de los demás. Los esclavos no, no es posible liberarse de la humillación con la elaboración racional de que el que le humilla está por fuera de su mundo interno.

No se trata, según Margalit, de que nuestros derechos han sido violados, sino que somos incapaces de exigirlos:

El requisito mínimo a la hora de reivindicar los propios derechos es que, cuando menos, la víctima sienta indignación contra las personas que la están maltratando. Lo mínimo que se espera de una víctima es que se rebele contra el daño que se le causa y contra quien se lo causa (1997: 40).

Este "requisito mínimo" (la indignación) es lo que hace detonar las luchas por el reconocimiento. Para Honneth son precisamente estos sentimientos negativos (resentimiento, indignación) la raíz de todo movimiento o denuncia social. La indignación es resultado de la conciencia de los individuos de una injusticia derivado de las posibles patologías sociales.

Según Honneth sólo aquellos que tienen autoconciencia de su dignidad son susceptibles de recibir la herida como moral, de lo contrario, la entenderán como desgracia, violencia o daño físico. Por ello dice Aristóteles (R, 137a) que "es en razón de su superioridad por lo que se enfurecen los hombres". Esta superioridad equivale a la dignidad o el status de una persona en tanto que persona y que espera no solo no ser menospreciada sino también no sentirse menospreciada. Pero volvamos a la pregunta: ¿qué pasa en los casos como el del 
sumiso tío Tom, mencionado por Margalit, o el de una esclava maltratada cuyo espíritu está agotado, que señala Nussbaum (2003), en los que no hay ninguna respuesta de autoafirmación? De acuerdo con la perspectiva de reconocimiento de Honneth, en los casos en que la persona no es consciente, o no reflexiona en términos positivos sobre su bienestar, no habría lugar para la humillación, pues

sólo puede ofenderse moralmente a aquellos seres vivos que se refieren reflexivamente a su propia vida en el sentido de que su voluntad está orientada por su propio bienestar; pues sin una referencia a los estándares de calidad de la propia vida no se puede explicar de ningún modo lo que perjudica o daña a una persona cuando, en lugar de meros daños, accidente o necesidad, hablamos de ofensas morales (Honneth 1999: 26).

Si aceptamos esta afirmación, así como la humillación o el desprecio en función del respeto y del reconocimiento, como sostienen Honneth y Margalit, tendríamos que aceptar consecuencias como las siguientes; para empezar, en el caso de los esclavos no habría propiamente ofensa moral y es por ello que ni el tío Tom ni la esclava sienten realmente ira contra su amo, pues ninguno cree realmente en el valor de su propia integridad y dignidad. Mientras crean que lo que se está dañando no tiene ningún valor, no habrá lugar a la cólera. En segundo lugar, y siguiendo esta dinámica, el amo tampoco estaría humillando, pues para que el acto de humillar cumpla su propósito (es decir, quitarle al otro su valor de humano) es necesario creer que la víctima, el esclavo en este caso, es consciente de que posee un valor humano intrínseco; de ahí que Margalit insista en que "la humillación presupone, por definición, la humanidad del humillado" (1997: 95). Sin embargo, Margalit sostiene que más allá de que el esclavo o cualquier persona reciban o no el acto como humillante, el esclavo merece respeto. Pero pareciera que tal respeto es una condición que está en manos de quien ostenta el poder o está en condiciones de decidir si respeta o no al otro.

De otra parte, tendríamos que afirmar que aquellos que por distintas razones "no se refieren reflexivamente a su propia vida", o no tienen "la conciencia concomitante de no ser reconocido en la propia idea de sí', o no son conscientes de que aquella acción "intencionalmente desdeña su bienestar en un aspecto esencial" (Honneth) no sufrirían, en sentido estricto, heridas morales o injusticias, sino "tan solo" físicas. En palabras de Margalit: "Parece que estas personas [aquellas que no se preocupan de sus intereses] prescinden de aquello que más debería importarles: que sus intereses fuesen respetados. Quienes carecen de este tipo de intereses de segundo orden carecen de respeto hacia sí mismos" (1997: 42). Debemos dejar cuando menos planteadas las siguientes preguntas: ¿es necesario que ocurra tal "darse cuenta", aquella conciencia del propio respeto vulnerado, para que la acción constituya una injusticia?, ¿no 
estaríamos haciendo depender la injusticia de la conciencia de quien la padece?

Sin duda es acertado el llamado de Honneth sobre la necesidad de "despertar" ese saber respecto al propio respeto (o ese sentir) y hacer conscientes a quienes sufren la humillación (el agravio o la crueldad) de que no están solamente frente a una herida física, sino a una herida moral, a una injusticia. La indignación y los demás sentimientos que Honneth llama negativos juegan, pues, un papel fundamental para la comprensión y transformación de la moralidad. Por ello quisiera finalizar afirmando que el descuido o abandono de las emociones, que están estrechamente vinculadas al respeto y el reconocimiento, llevaría consigo el aislamiento humano y la pérdida de conciencia de la propia contingencia.

Cita Rousseau en el Emilio el siguiente verso de Virgilio: "No se compadecen jamás en otros sino los males de los que no se cree exento uno mismo" (Eneida, I) y añade, a modo de ejemplo: “¿Por qué los reyes carecen de piedad hacia sus súbditos? Es que ellos cuentan con no ser hombres jamás" (Rousseau 1985: 256). Quien no sea capaz de experimentar resentimiento, indignación, piedad o compasión, que se derivan del respeto por la dignidad propia y de los demás, no es capaz tampoco de comprender el significado de la moralidad como humanidad, por lo cual no puede participar de las relaciones interpersonales, ni del lenguaje o de otras expresiones no verbales de la vida moral.

\section{Referencias bibliográficas:}

Aristóteles. (1999) Retórica, Gredos, Madrid.

(1993) Ética nicomáquea. Ética eudemia, Gredos, Madrid.

Bandura, A. (2002) "Selective Moral Disengagement in the Exercise of Moral Agency", en: Journal of Moral Education, No 31.

Erikson, E. (1956) Insight and Responsability W.W. Norton and Company, Inc., New York.

Garretón, R. (2004) “¿Qué es ser «torturador»?”, en: De la tortura no se habla, Catalonia, Santiago de Chile.

Hartling, L. and Luchetta, T. (1999) "Humiliation: Assessing the impact of Derision, Degradation, and Debasement", en: The Journal of Prevention, Vol. $19, \mathrm{~N}^{\circ} 4$.

Honneth, A. (1992) "Integridad y desprecio. Motivos básicos de una concepción de la moral desde la teoría del reconocimiento", en: Revista Isegoría, $\mathrm{N}^{\mathrm{o}} 5$. 
(1996) "Reconocimiento y obligaciones morales", en: Revista internacional de filosofia politica, $\mathrm{N}^{\circ} 8$.

(1999) "Entre Aristóteles y Kant. Esbozo de una moral del reconocimiento", en: Logos: Anales del Seminario de Metafísica. Katz, Madrid.

(2012) Reificación. Un estudio en la teoría del reconocimiento,

Levi, P. (1997) Entrevistas y conversaciones, Península, Barcelona.

(2000) Los hundidos y los salvados, Muchnik Editores, Barcelona.

Margalit, A. (1997) La sociedad decente, Barcelona, Paidós.

Mead, G.H. (1973) Espíritu, persona y sociedad, Paidós, Barcelona.

Nussbaum, M. C. (2003) La terapia del deseo. Teoría y práctica en la ética helenística, Paidós, Barcelona. ley, $\overline{\text { Katz, Argentina. }}$

(2006) El ocultamiento de lo humano. Repugnancia, vergüenza y

Rorty, R. (1995) "Derechos humanos, racionalidad y sentimentalismo", en: Batallas Éticas, Nueva Visión, Buenos Aires.

Rosero, E. (2007) Los ejércitos, TusQuets, Barcelona.

Rousseau, J.J. (1985) Emilio, Edaf, Madrid.

Scheler, M. (2004) Sobre el pudor y el sentimiento de vergüenza, Sígueme, Salamanca.

Séneca, L.A. (1986) De ira, Alianza, Madrid.

Sontag, S. (2004a) Ante el dolor de los demás, Alfaguara, Bogotá. Bogotá. (2004b) “Ante la tortura de los demás", en El Malpensante, № 55,

Uribe, A. (2007) "La sociedad esclavista en el Nuevo Reino de Granada: una sociedad humillante", en: Revista de Estudios Sociales, Universidad de los Andes, $\mathrm{N}^{\mathrm{o}} 26$.

Zimbardo, P. (2008) El efecto Lucifer. El porqué de la maldad, Paidós, Barcelona.

Zimbardo, P., Haney, C., Banks, W.C. y Jaffe, D. (1986) "La psicología del encarcelamiento: privación, poder y patología”, en: Revista de Psicología Social, España. 